\title{
Changes in commonality scores as a function of task and time: Implications for PA learning'
}

\author{
Sydelle S. Shapiro \\ AUSTEN RIGGS CENTER, STOCKBRIDGE, MASS.
}

\begin{abstract}
Abstraet
An assumption made in the use of associative strength as a variable in PA learning is that the norms from which it is taken reflect stable group characteristics. The present study tested this by comparing groups which had received PA training designed to change their responses to a WA test with a control group which had received no specific training. The results showed that all groups, regardless of condition, changed more than $50 \%$ of their associations and that all groups increased in commonality.
\end{abstract}

\section{Problem}

Word association (WA) norms are frequently used to develop indices of associative strength. When WA strength is used as a variable in learning tasks it is presupposed that the index reflects fairly stable group characteristics. This would suggest that even if specific learning tasks could be devised which would change an experimental group's set of responses to a WA test, a control group which had not been subjected to any differential training should continue to respond as it had when originally tested. Such changes can be measured by the use of the commonality score (C). The $\mathrm{C}$ is the number of responses which a $\mathrm{S}$ gives which is the same as the primary (the most frequent associate) for the group.

The present study tested the effect of learning a list of high frequency associates on the C of one group of Ss. the effect of learning a list of idiosyncratic associates on the $\mathrm{C}$ of a second group, and the effect of time on the C of a control group.

\section{Method}

The Ss were 48 eighth grade children, 24 boys and 24 girls who had scored in the middle range for $\mathrm{C}$ on a WA test taken two months prior to the experiment, and scored on the basis of Shapiro's (1963) norms. The range of $\mathrm{C}$, based on responses to 30 words was $13-15$. The Ss were divided into three groups of eight boys and eight girls each. Group I was given a paired associate (PA) learning task consisting of eight pairs of stimulus words and their primaries as responses i.e., boy-girl; paymoney; wax-floor; rib-bone; jet-plane; new-old; faraway; hop-jump. The list was randomly presented at a $2: 2$ rate on a Stowe memory drum. Ss task was to anticipate responses to a criterion of one perfect trial. Immediately following criterion, the Ss were given a WA retest consisting of the same 30 words on which they had been previously tested two months before. The stimulus words of the PA list were included in the 30 words. Group II followed the same procedure except that the response words on the PA task consisted of very low frequency associates i.e., boy-like; pay-hour; wax-cast; rib-talk; jet-water; new-stamp; far-knife; hop-push. Group III acted as a control group. It did not receive any $\mathrm{PA}$ training but merely took the WA retest.

\section{Results}

Group I reached criterion in 3 trials while Group II required 8.8 trials to reach criterion. A t-test showed this difference to be significant $(t=4.7 ; \mathrm{df}, 30 ; \mathrm{p}<.01)$.

Table 1 shows percentage comparisons between the WA test and retest of the 30 words. All groups, including the control (Group III) increased in C. The largest increase, that of Group I reflects both the increase obtained across all groups and also a specific increase in the subgroup of words i.e., the words and their primaries which were contained in the PA task. Group II and Group III scored about the same in all categories.

All groups show that well over $50 \%$ of the WA changed on the retest. The protocols of all $48 \mathrm{Ss}$ were inspected and showed that in 40 cases at least half of the associations changed on the retest. In order to assess the nature of this change, 10 protocols were chosen at random from the control group (Group III) and were inspected. Of 54 responses which became primaries on the retest, $43 \%$ were within the first four most popular responses on the group norms. Of 33 responses which changed from the primary to another word, $42 \%$ became words which were among the first four most popular responses.

\section{Diseussion}

The results described help to explain the failure to get a differential effect using word association frequencies as observed by Jenkins (in press) using adults. Although response hierarchies may be stable for groups, they are fluid for individual Ss. In PA studies where this variable

Table 1. Test-retest Percentage Scores for Selected Characteristics on 30 Item Word Association Test

\begin{tabular}{|c|c|c|c|}
\hline Characteristics & Group I & Group II & $\begin{array}{l}\text { Group III } \\
\text { (Control) }\end{array}$ \\
\hline $\mathrm{C}$ (test) & 45.7 & 43.3 & 47.7 \\
\hline $\mathrm{C}$ (retest) & 62.3 & 50.7 & 51.7 \\
\hline WA Changes & 58.3 & 57.7 & 55.0 \\
\hline Primaries lost on retest & 11.3 & 12.0 & 14.3 \\
\hline $\begin{array}{l}\text { Words which became } \\
\text { primaries on retest }\end{array}$ & 28.0 & 20.0 & 18.7 \\
\hline $\begin{array}{l}\text { Subgroup (8): Primaries } \\
\text { lost on retest }\end{array}$ & 3.7 & 13.7 & 16.2 \\
\hline $\begin{array}{l}\text { Subgroup ( } 8) \text { : Words which } \\
\text { became primaries on retest }\end{array}$ & 42.5 & 13.7 & 17.5 \\
\hline
\end{tabular}


is effective, the levels tested are usually very high and very low frequencies and the Ss are grade school children. (Castaneda, Fahel, \& Odom, 1961; McCullers, 1961; Shapiro, in press). Wicklund, Palermo, \& Jenkins (1964) used an intermediate list as well as a list of primaries and a list of very low frequencies. While significant differences were obtained between the high frequency list and the other two, there was no appreciable difference between the intermediate and low frequency list.

It seems reasonable to conclude that verbal response hierarchies can make only gross predictions in the PA learning of children. It may be that with adults language habits are so strong that one exposure to a list is sufficient to change the response strengths of the entire hierarchy. In children this also occurs, but notover the entire hierarchy. Rather, it can be conceived of as occurring within a range of values from any specified strength. This would allow for differences at the extremes but not at the intermediate levels.
References

CASTENEDA, A., FAHEL, L. S., \& ODOM, R. Associative characteristics of sixty-three adjectives and their relation to verbal paired associate learning in children. Child Develpm., 1961, 32, 297-305.

JENKINS, J. J. The 1952 word associations norms. In L. Postman (Ed.), Norms of word associations. New York: Academic Press, in press.

MCCULLERS, J. C. Effects of associative strength, grade level, and interpair interval in verbal paired associate learning. Child Develpm., 1961, 32, 773-778.

SHAPIRO, S. S. Word associations to CVCs by grade-school-aged children. Department of Psychology, University of Massachusetts, Amherst, Massachusetts, 1963.

SHAPIRO, S. S. Paired associates learning in children. J. verbal Learn. verbal Behav., in press.

WICKLUND, D. A., PALERMO, D. S., \& JENKINS, J. J. The effects of associative strength and response hierarchy on paired-associate learning. J. verbal Learn. verbal Behav., 1964, 3, 413-420.

\section{Note}

1. This work was supported by a Public Health Service grant HD 01014-01 from the National Institute of Child Health and Human Development. The author is indebted to Mr. James P. Reynolds, Superintendant of Schools and Mr. William A. Tully, Principal of South Junior High, Pittsfield, Mass., for their cooperation. 